\title{
Statistical variations of lower atmospheric turbulence and roles of inertial gravity waves at a middle latitude radiosonde site
}

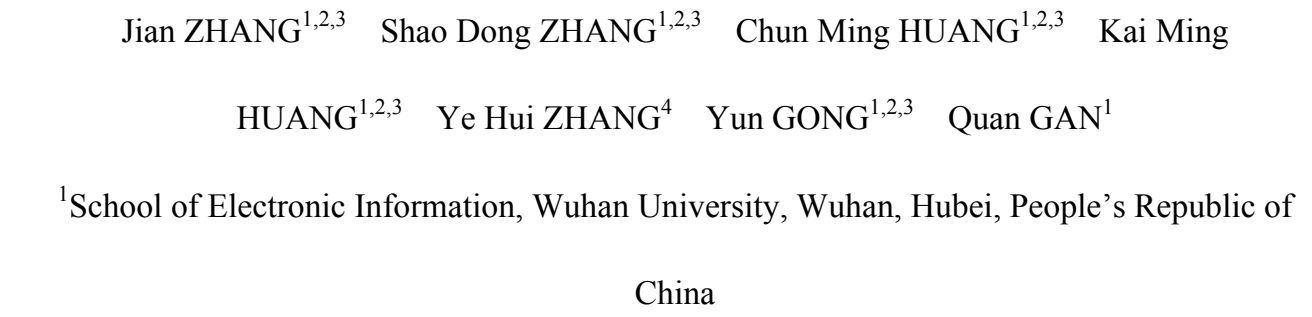

China

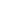

${ }^{2}$ Key Laboratory of Geospace Environment and Geodesy, Ministry of Education, Wuhan, Hubei, People's Republic of China

${ }^{3}$ State Key Laboratory of Information Engineering in Surveying, Mapping and Remote Sensing, Wuhan University, Wuhan, People's Republic of China

${ }^{4}$ College of Hydrometeorology, Nanjing University of Information Science and Technology, Nanjing, People's Republic of China

15

6

7

Corresponding author: Zhang Shaodong

$$
\text { Phone: +86-27-68762292-8006 }
$$

Fax code: $+86-27-68762292-8006$

Email Address: zsd@whu.edu.cn

Zip code: 430079 


\section{Key points:}

Abstract. Activities about turbulence and gravity waves are crucial for the understanding of the dynamical processes in the lower atmosphere. Thus, this study presents the long-term variations of turbulence and their associations with the Richardson number $R i$ and gravity waves by using a high-resolution radiosonde dataset from Miramar $\operatorname{Nas}\left(32.8^{\circ} \mathrm{N}, 117.1^{\circ} \mathrm{W}\right)$. Seasonal cycles and lognormal distribution are the two main characteristics of turbulence. The amount of turbulence can be increased where $R i$ exceeds any critical value, which suggests that the threshold Ri may not be an optimal predictor of the existence of turbulence, whereas a low $R i$ can lead to large and abundant turbulent energy dissipation rates. In general, dissipation rates from the radiosonde quantitatively agree with results from the neighboring MST radar given by Nastrom and Easton (2005), whereas an encouraging argument is reached in terms of the diffusion rate. The propagating gravity waves in the lower atmosphere, especially in the middle troposphere and the tropopause regions, can reduce $R i$. Therefore, enhanced turbulent mixing is expected. Other roles of gravity waves in turbulent flow are that breaking waves and the temporal variations of waves may be occasionally transferred to turbulence and can roughly estimate dissipation rates at different heights.

Keywords: The Thorpe sort method; High-resolution radiosonde; Turbulent energy dissipation rate; Gravity wave

1. The Thorpe-resolved turbulent energy dissipation rate is only quantitatively consistent with radar results, whereas encouraging argument is found for the diffusion rate. 
2. The Richardson number may not be a reliable predictor of the existence of turbulence and can be reduced by propagating inertial gravity waves.

3. Wave-induced turbulence occasionally occurs in tropopause regions, and the temporal variations of waves can roughly estimate turbulence at different heights.

\section{Introduction}

Tropospheric and lower stratospheric turbulence is attracting considerable interest due to its important role in determining dynamic atmospheric and stratosphere-troposphere exchanges (Dutta et al., 2009); heat, momentum, mass, and constituent redistribution (Fritts et al., 2012); and chemical diffusion; such turbulence is also economically important for commercial aircraft (Sharman et al., 2012). Therefore, much attention has been paid over the past decades to the variation and generation of turbulence.

Experimental observations, such as radar and sounding, are fundamental to the comprehensive understanding of the characteristics of turbulence. Radar observations with large power-aperture and high spatial resolution are necessary for the accurate detection of turbulent air according to the assumption that the Bragg scale lies within the inertial subrange of turbulence (Wilson et. al., 2005). VHF radars are the most widely adopted among the different radar types (Hocking and Mu, 1997; Nastrom and Eaton, 1997; Satheesan and Murthy, 2002; Fujiwarea et al., 2003; Wilson et. al., 2005; Das et al., 2010; Mega et al., 2010; Kantha and Hocking, 2011; Li et al., 2016). High-resolution soundings, which include radiosonde, dropsonde, and some specially designed soundings with spatial resolutions ranging from dozens of meters to even a few millimeters, are utilized for investigating the 
67 fine structure or statistical distribution of turbulence (such as Luce et al., 2001; Gavrilov et al., 2005; Lovejoy et al., 2007; Theuerkauf et al., 2011, Schneider et al., 2015). Soundings with extremely high spatial resolution are especially important for the precise revelation of the inner structure of turbulence, but these campaigns are sparse, and their observation duration is quite limited. Other instruments, including airborne equipment (Pavelin et al., 2002; Cho et al., 2003; Whiteway et al., 2004), lidar (Liu, 2009) and OH airglow (Yamada et al., 2001), also provide some insights into turbulence at different heights. Previous studies have indicated that the strongest and weakest turbulence intensities are in the mesosphere and the stratosphere, respectively, and that turbulence exhibits evident seasonality from the lower atmosphere up to the mesosphere and the lower thermosphere (Lübken, 1997; Nastrom and Eaton, 1997; 2005; Rao et al., 2001). In addition, observations at different latitudes (Fujiwara et al., 2003; Dutta et al., 2009; Mega et al., 2010; Ueda et al., 2012) have revealed significant latitudinal variations of atmospheric turbulence. Instabilities in the lower atmosphere, which are generally connected with turbulence, not only limit the amplitude of shear and waves but also contribute to generating turbulence; furthermore, breaking gravity waves are a dominant source of turbulence in the mesosphere and the lower thermosphere (Fritts et al., 2003). Instabilities can be divided into two categories according to Richardson number $R i$. The first category is convective instability $(R i<0)$, which favors strong turbulence (Fritts et al., 2012) and should be rare in the free atmosphere, and the other is dynamical instability $(0 \leq R i<1 / 4)$, which tends to excite weak turbulence (Thorpe, 1973). Additionally, various numerical simulations have presented processes of converting breaking gravity waves to turbulence (such as Fritts et al., 1996; Liu et al., 1999). Breaking gravity waves and instabilities differ in 
timescales and mixing characteristics (Fritts and Alexander, 2003). Although local instabilities are crucial for the generation of turbulence in the troposphere and the lower stratosphere, recent studies have suggested that propagating gravity waves in the lower atmosphere, especially in tropopause regions, can reduce $R i$ and promote instabilities (Sharman et al., 2012; Kunkel et al., 2014). Moreover, in the lower atmosphere, gravity waves can break down into turbulence (Whiteway et al., 2004) and may be strongly related to shear instability (Zhang et al., 2009).

One of the main issues about VHF radars is lack of temperature measurement. Thus, the multiple correlations between turbulence, local instabilities, and inertial gravity waves need to be comprehensively investigated by observation. Additionally, although the MST radars at Gadanki $\left(13.5^{\circ} \mathrm{N}, 79.2^{\circ} \mathrm{E}\right)$, Shigaraki $\left(34.5^{\circ} \mathrm{N}, 136.0^{\circ} \mathrm{E}\right)$, White Sands Missile Range $\left(34.4^{\circ} \mathrm{N}\right.$, $\left.120.3^{\circ} \mathrm{W}\right)$, and Andøya $\left(69.03^{\circ} \mathrm{N}, 16.04^{\circ} \mathrm{E}\right)$ provide some valuable long-term analyses of turbulence at different latitudes in the free troposphere and the lower stratosphere (such as Nastrom and Eaton, 1997; Furumoto and Tsuda, 2001; Das et al., 2010; Li et al., 2016), the inter- and intra-annual variations of turbulence are not globally understood. Radiosonde and its association with the Thorpe sorting process can reveal the correlations between turbulence, local instabilities, and gravity waves and summarize long-term turbulence trends.

By employing the Thorpe sort method for examining the distribution of turbulence and the broad spectral method proposed by Zhang et al. $(2012 ; 2013)$ for the extraction of inertial gravity waves, we aim to outline the statistical characteristics of turbulence parameters and the roles of inertial gravity waves in generating turbulence with the help of high-resolution ( 5 m) radiosonde data at Miramar $\operatorname{Nas}\left(32.8^{\circ} \mathrm{N}, 117.1^{\circ} \mathrm{W}\right)$. This paper is divided into five 

reduction procedures and the Thorpe sort method. Section 3 presents the statistical variations of turbulence parameters, and Section 4 discusses the associations with gravity waves. Finally, Section 5 states the conclusion.

\section{Database}

Radiosonde covers multiple parameters, including pressure, temperature, and relative humidity, using especially designed sensors and horizontal wind from the GPS tracking system and can obtain resolutions of $0.01 \mathrm{hPa}, 0.01{ }^{\circ} \mathrm{C}, 0.1 \%$, and $0.1 \mathrm{~m} / \mathrm{s}$ for these parameters. The US National Oceanic and Atmosphere Administration (NOAA) has been providing high-resolution radiosonde data with sample rates reaching $1 \mathrm{~Hz}$ (corresponding to roughly $5 \mathrm{~m}$ sampling in altitude) since 2005 .

We utilize the site located at Miramar $\operatorname{Nas}\left(32.8^{\circ} \mathrm{N}, 117.1^{\circ} \mathrm{W}\right)$, that is, the site closest to the MST radar at White Sands Missile Range, California $\left(34.46^{\circ} \mathrm{N}, 120.33^{\circ} \mathrm{W}\right)$, which was adopted by Nastrom and Eaton $(1997 ; 2005)$. Thus, the radiosonde and radar results can be roughly compared. The time interval of the sondes ranges from May 2010 to April 2018 and is blank during September 2017 to December 2017. A total of 5398 soundings are launched at systematic observation times, such as 0000 UT and 0012 UT. Meanwhile, 434 profiles are ruled out, of which 394 profiles have burst heights lower than $20 \mathrm{~km}$ and 40 profiles are found to have glaring measurement errors through manual checking. Measurement errors are often caused by incorrect measurements of rising height. Consequently, 4964 operational profiles are kept. We choose $30 \mathrm{~km}$ as our upper height limit under the condition that $85.6 \%$ 
m) data. Meanwhile, a reduction of resolution is beneficial for reducing noise (Wilson et al., 2010) because the typical overturns in the lower stratosphere are generally less than a few tens of meters (Clayson and Kantha, 2008), but we keep the high resolution to effectively resolve the Thorpe scale. Another problem for radiosondes is the horizontal drift of balloons. Thus, the trajectories of balloons must be tracked. Figure 1 summarizes the cumulative map of horizontal trajectories for all the valid profiles up to the maximum threshold flight height, in which the purple square highlights the location of the neighboring MST radar. From this figure, we can note that most of the trajectories are restricted within 1.5 degrees in longitude and within 1 degree in latitude. Thus, we assume that the observations of soundings are localized.

\section{Methodology}

The Thorpe sort is an efficient method used in the study of oceanographical turbulent flow. In recent years, the application of this method to the atmosphere has been gaining interest. The essential issue for the Thorpe method is identifying true overturns, whereas, especially in the weakly stratified troposphere, random instrumental noises or artificial inversions can contaminate a Thorpe sort. Thus, to distinguish true overturns from false ones, procedures for noise reduction must be carefully considered.

\subsection{Composite potential temperatures and noise reduction procedures}

The Thorpe sort method is based on the inversion of the potential temperature $\theta$, which 
can be considerably influenced by humidity and noises. The following procedures are applied to handle the two issues. The first step (1) is to assess composite potential temperature $\theta_{*}$, which is a combination of dry and moist saturated conditions. The thresholds of relative humidity for moist saturated air follow the empirical curves for clouds proposed by Zhang et al. (2010) and spatially decrease from approximately $90 \%$ at $3 \mathrm{~km}$ to nearly $80 \%$ at $10 \mathrm{~km}$. The squared Brunt-Väisälä frequencies $N_{d}^{2}$ and $N_{m}^{2}$ are estimated under the assumption of dry and a moist models, respectively. The exact calculation of $N_{m}^{2}$ follows Eq. (5) in Durran and Klemp (1982), and the equation parameters, such as the latent heat of vaporization, are based on NOAA (1976). Then, the final squared Brunt-Väisälä frequency $N^{2}$ is a composite of $N_{d}^{2}$ and $N_{m}^{2}$ and is then iterated for $\theta_{*}$. The second procedure involves (2) the trend-to-noise ratio (TNR), which is used to estimate the noise degree of measurement (Wilson et al., 2010; 2011). The instrument noises are caused by the measurement of temperature rather than of pressure. As in Wilson et al. (2011), the noise variance of temperature can be obtained through the following procedure. Temperature profiles are split into segments of $200 \mathrm{~m}$, and a linear tend is found and removed within a segment. The noise variance of the temperature is half the variance of the first differences of the residual. Finally, smoothing with a bin of $100 \mathrm{~m}$ is applied to the noise variance of the temperature. The local TNR at the $i$ th height can be estimated as

$$
\varsigma_{i}=\frac{\theta_{*(i+1)}^{s}-\theta_{*(i-1)}^{s}}{2 \sigma_{N}}
$$

where $\theta_{*}^{s}$ is the sorted profile of $\theta_{*}$ and $\sigma_{N}$ is the standard deviation of the noise of $\theta_{*}$.

$\sigma_{N}$ is inferred from $\left(\frac{1000}{P}\right)^{2 / 7} \sigma_{T}$, where $P$ is the pressure and $\sigma_{T}$ is the standard 
deviation of the temperature noise. $\checkmark$ should be less than a threshold if the noise is severe, and the critical value is typically set to 1.5 ; false overturns are rejected when $\varsigma<1.5$. Bulk TNR is introduced to determine the overall quality of $\theta_{*}$ and defined as

$$
\bar{\varsigma}=\frac{\theta_{*(n)}-\theta_{*(1)}}{(n-1) \sigma_{N}}
$$

where $n$ is the number of data points. We follow Kantha and Hocking (2011) and estimate $\bar{\zeta}$ in the troposphere and the stratosphere separately. $\bar{\zeta}$ presents the background stratification and should be too small (close to a unit or higher) if the stratification is too weak (moderate or strong), thereby invalidating the profiles of the Thorpe scale when $\bar{\varsigma}<0.8$. The third procedure involves (3) the intermediate profile of $\theta_{*}$, which is used for final sorting. It is computed under the assumption that the difference of two adjacent points of $\theta_{*}$ should exceed the noise of $\theta_{*}$. Detailed explanation can be found in Kantha and Hocking (2011).

\subsection{Thorpe sort method}

In the investigation of atmospheric turbulence, the energy dissipation rate $\varepsilon$ can be expressed in terms of the Ozmidov length $L_{O}$ (Ozmidov, 1965) as

$$
\varepsilon=L_{O}^{2} N^{3}
$$

where $N$ is the Brunt-Väisälä frequency deduced from the sorted monotonic potential temperature. The detailed derivation process is presented by Riley and Lindborg (2008). $L_{O}$ defines the length scale at which the equivalent magnitude of inertial and buoyancy forces is applied to a particle (Gavrilov et al., 2005) or represents the largest eddy unaffected by buoyancy (Crawford, 1986). The Thorpe length $L_{T}$ can gauge the maximum scale that has sufficient kinetic energy for inversion (Riley and Lindborg, 2008). Some ocean explorations 
(such as Crawford, 1986; Thorpe, 2005) have proven the existence of a proportional relationship between $L_{O}$ and $L_{T}$, that is, $L_{O}=c L_{T}$, where $c$ is a proportional coefficient near unity. However, recent studies have revealed a large discrepancy between the Ozmidov and Thorpe lengths. For example, Mater et al. (2013) demonstrated that the argument between $L_{O}$ and $L_{T}$ holds only under comparable timescales of turbulence and buoyancy; Yagi and Yasuda (2013) emphasized that this ratio should be achieved by a comparison with the directly measured energy dissipation rate; Wijiesekera et al. (1993), Mater et al. (2015), and Schneider et al. (2015) presented a clear lognormal distribution of $c^{2}$ and suggested that the ensemble mean seems to be possible by Thorpe analysis; Fritts et al. (2016) suggested that $L_{O} / L_{T}$ is highly variable with event type and time and tends to increase with time, whereas it can be defined with suitable averaging on the basis of event type and character. In conclusion, turbulence in stably stratified flows is quite complex, and a lognormal distribution of $c^{2}$ is likely. The proportionality relationship will settle down to a nearly constant value once Kelvin-Helmholtz billows break down into turbulence (Gavrilov et al., 2005). In addition, Scotti (2015) stated that oceanic $c^{2}$ is substantially skewed in the convection-driven turbulence than in the shear-driven model. However, convectively unstable flows can be occasional in the planetary boundary layer and are rare in the free atmosphere. Accordingly, in the present study, we investigate the free atmosphere only and exclude heights below $2 \mathrm{~km}$. Several studies have found good agreement between radar and radiosonde results with $c^{2}=1$, such as recent works by Kantha and Hocking (2011) and Li et al. (2016). Considering that the present study aims to analyze the statistical results of turbulence and that the ensemble mean may reduce the negative influence from a variable $c^{2}$, 
220 we choose $c^{2}=1$.

221 Supposing the intermediate profile of $\theta_{*}$ at the original position $z_{i}$ needs to be moved

222 to $z_{j}$ to eliminate overturn, we obtain the corresponding height difference $d_{i}=z_{i}-z_{j}$ as the Thorpe displacement $L_{D}$, whose root mean square over an overturn layer is the Thorpe length $L_{T}$. An overturn layer is a region where $\sum_{i=1, n} L_{D}(i)=0$ and $\sum_{i=1, k} L_{D}(i)<0$ for any $k<n$. False overturns are removed under the criterion described by Wilson et al. (2010) from a statistical point of view. The variations of $\theta_{*}$ in the range of an overturn should exceed $99 \%$ of the noise range in the equivalent size of the overturn. Wilson et al. (2010) tabulated the relationship between overturn size and threshold TNR. Finally, the energy dissipation rate can be formulated by $\varepsilon=c^{2} L_{T}^{2} N^{3}$.

Then, eddy diffusion coefficient $K, K=\gamma \varepsilon N^{-2}$, can be obtained from the turbulence energy equilibrium equation under a simplified hypothesis, as illustrated by Thorpe (2005), where $\gamma=\frac{R i_{f}}{1-R i_{f}}$ is the mixing coefficient and $R i_{f}$ is the flux $R i$. The commonly used value is $R i_{f}=0.25$ (Ueda et al., 2012), which corresponds to $\gamma=0.33$.

\subsection{Typical vertical analysis}

Figure 2 shows composite potential temperature $\theta_{*}$; relative humidity and empirical predictions for clouds; squared Brunt-Väisälä frequency $N^{2}$; zonal and meridional winds $u$ and $v$; local and bulk TNRs $\varsigma$ and $\bar{\zeta}$, respectively; Thorpe displacement $D_{T}$; Thorpe length scale $L_{T}$; and the logarithms of energy dissipation rate and eddy diffusion coefficient $\log _{10} \varepsilon$ and $\log _{10} K$, respectively, at 0012 UT on March 12, 2018.

Figure 2(a) shows that except for some observable overturns that indicate unstable layers,

$\theta_{*}$ gradually increases with altitude. Figure 2(c) illustrates that $N^{2}$ varies from about 

several heights below $10 \mathrm{~km}$, especially at the cloud layers (as shown in Fig. 2(b)), $N^{2}$ becomes negative, implying strong local convective instability. Additionally, strong winter jet streams prevail at approximately $12 \mathrm{~km}$ with maxima exceeding $50 \mathrm{~m} / \mathrm{s}$, and the meridional wind is much smaller compared with the zonal wind. Figure (2e) shows that $\bar{\zeta}$ equals 0.86 and 1.72 in the troposphere and the stratosphere, respectively, and low $\varsigma$ values eliminate most of the tropospheric dissipation rates, especially the regions in 4-8 and 10-13 $\mathrm{km}$. Figure 2(f) presents that large overturns basically yield below $12 \mathrm{~km}$ and have values of around $150 \mathrm{~m}$ for $D_{T}$ and approximately $75 \mathrm{~m}$ for $L_{T}$. $\varepsilon$ substantially varies from $10^{-6}$ $\mathrm{m}^{2} \mathrm{~s}^{-3}$ to $0.01 \mathrm{~m}^{2} \mathrm{~s}^{-3}$ and has increased values at $10 \mathrm{~km}$. Moreover, it is considerably excluded by $\varsigma$, especially in the lower and middle free troposphere. $K$ varies from $10^{-1} \mathrm{~m}^{2} \mathrm{~s}^{-1}$ to 10 $\mathrm{m}^{2} \mathrm{~s}^{-1}$ and has nearly a similar height variation as does $\varepsilon$.

\section{Background and turbulence parameters} reduction procedures. To obtain additional samples in each height bin and month, the monthly results in the subsequent analysis are regarded as a spatial composite of a segment of $100 \mathrm{~m}$.

\subsection{Background}

Background atmosphere in dynamical and thermal domains is crucial for a complete understanding of the activities of turbulence or gravity waves. The monthly means of zonal wind, vertical shear of horizontal wind speed, and the squared Brunt-Väisälä frequency are 
highlighted in Fig. 3. The dotted dark lines denote the cold point tropopause (CPT) heights.

The wind shear $S$ is estimated by zonal and meridional wind components, that is,

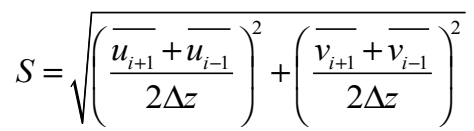

where $\Delta z=5 \mathrm{~m}$ is the spatial resolution of the data. The bars represent that a moving average of $100 \mathrm{~m}$ is applied to $u$ and $v$ to diminish the effects of instrumental noises. $R i$, which is derived from $R i=N^{2} / S^{2}$, is introduced to indicate the instability of the atmosphere. The instantaneous profile of $N^{2}$ is strongly influenced by small-scale movements. Thus, we perform a moving average with a bin of $100 \mathrm{~m}$ on $N^{2}$ to exclude the influence of perturbations from the calculations of $R i$. Previous studies (such as Haack et al., 2014) have indicated that turbulence can extend beyond the critical value of $R i$ (for instance, $R i=1 / 4$ ).

Zonal wind shows strong seasonal cycles, and winter jet streams prevail from December to April at $7 \mathrm{~km}$ to $15 \mathrm{~km}$ with maxima of approximately $40 \mathrm{~m} / \mathrm{s}$. Jet streams are an important source of jet-generated gravity waves (Fritts et al. 2016) and an important contributor to shear instability in the upper and lower edges of jet streams. Fig. 3(a) highlights that wind shears are more severe at $12 \mathrm{~km}$ to $21 \mathrm{~km}$ than at other heights and exhibit an apparent inter-annual variation. Notably, strong shears prevail in the CPT region, which is typically at around 17 $\mathrm{km}$. Considerable wind shear is crucial for Kelvin-Helmholtz billows and a source of gravity waves (Pramitha et al., 2015). Monthly $N^{2}$ displays a clear inter-annual variation above 11 $\mathrm{km}$ and presents weaker stability at $7-11 \mathrm{~km}$. The variations of turbulence may be deeply influenced by the variation patterns of $N^{2}$ due to the fact that the fundamental of the Thorpe sort method is $N^{2}$.

As shown in Fig. 4, we calculate the monthly occurrence rate for $R i<1 / 4 \quad\left(R i_{C}\right.$ 
hereafter) and $1 / 4 \leq R i<1 \quad\left(R i_{1}\right.$ hereafter). The values of $R i_{C}$ in the troposphere and in the lower stratosphere considerably differ and decrease from approximately $20 \%$ below $10 \mathrm{~km}$ to around $7.5 \%$ in the tropopause region and to nearly $2 \%$ in the lower stratosphere. Figure $4(\mathrm{~b})$ presents that $R i_{1}$ is significantly larger than $R i_{C}$ at almost all the heights and has larger values reaching $50 \%$ in the tropopause region; these large values may be caused by the intense wind shear.

\subsection{Turbulence parameters}

Monthly and seasonal (December-February: winter; March-May: spring; June-August: summer; September-November: fall) means of $L_{T}, \varepsilon$, and $K$ are summarized in Fig. 5. $L_{T}$ varies from around $80 \mathrm{~m}$ in the lower free troposphere to approximately $40 \mathrm{~m}$ in the middle troposphere and decreases to around $15 \mathrm{~m}$ in the lower stratosphere, as illustrated in Fig. 5(a) and 5(d). Additionally, local enhancement of $L_{T}$ can be seen at nearly $9 \mathrm{~km} . \quad \varepsilon$ is always regarded as an index of turbulence strength, reflecting the quantity and efficiency of kinetic energy converted to heat by viscous forces. The logarithm of $\varepsilon$ ranges from -2.9 at $2 \mathrm{~km}$ to -3.5 at $5 \mathrm{~km}$ and to -3.0 at $9 \mathrm{~km}$ and increases with latitude in the lower stratosphere. A seasonal cycle can be found above $5 \mathrm{~km}$, and a significant enhancement of $\varepsilon$ from 2013 to 2017 in winter can be observed in the lower stratosphere. The temporal-spatial variations of $\log K$ have nearly the same pattern as does $\log \varepsilon$ and have decreased value from around zero in the troposphere to approximately -0.8 in the lower stratosphere, as demonstrated in Fig. 5(c) and 5(f).

By analyzing the results from the MST radar at Vandenberg Air Force Base $\left(34.46^{\circ} \mathrm{N}\right.$, $\left.120.33^{\circ} \mathrm{W}\right)$, Nastrom and Eaton (1997) showed that the means of $\log \varepsilon$ fall between -3.5 

and -2.5 at all heights from $5 \mathrm{~km}$ to $20 \mathrm{~km}$ in all seasons and have an enhancement at $12 \mathrm{~km}$. Then, Nastrom and Eaton (2005) showed that $\log \varepsilon$ varies from -3.7 near $8 \mathrm{~km}$ to approximately -3.1 at $2 \mathrm{~km}$ and $21 \mathrm{~km}$, as demonstrated in Fig. 5(e). These radar results are generally consistent with radiosonde findings, but significant differences can be noted from 9 $\mathrm{km}$ to $12 \mathrm{~km}$. This discrepancy can be interpreted as follows. Dissipation rates from radars are resolved from the wind spectrum but understood by unstable overturn from a Thorpe sort. Furthermore, an encouraging argument can be found between the Thorpe-resolved diffusion rates and those from radar.

Figure 6 shows the histogram densities of the dissipation rates that match $R i<1 / 4$, $1 / 4 \leq R i<1$, and $R i \geq 1$. The number of dissipation rates that agree with $R i<1 / 4$ accounts for only $5.8 \%$ of the total values. This condition suggests that most of the turbulence cannot be explained by the local instabilities. However, $R i$ is greatly influenced by the spatial resolution of data and tends to be reduced by enhanced spatial resolutions. The dissipation rates that match $1 / 4 \leq R i<1$ account for $32.9 \%$, and the rest are beyond $R i=1$. This situation suggests that at least over half of the turbulence cannot be effectively interpreted by $R i$. The logarithm of $\varepsilon$ that corresponds to different $R i$ is all nearly lognormally distributed and has optimal values decreasing from -3.5 to -3.62 , which match $R i<1 / 4$ and $R i \geq 1$, respectively, and it appears to be more abundant and vigorous when $R i$ is lower. Moreover, Sharman et al. (2014) and Li et al. (2016) also suggested a lognormal distribution of dissipation rate.

\section{Gravity waves}


Previous studies have shown that wave and turbulence are closely related (such as Barat, 1982; Fritts and Alexander, 2003; Sharman et al., 2012); that is, wave energy is dissipated and converted to turbulence when the wave amplitude exceeds the instability threshold. Here, we study the possible role of gravity waves in generating turbulence. We can derive the continuous height variation of gravity wave perturbations by using the broad spectral method, which was proposed by Zhang et al. $(2012 ; 2013)$. In this technique, a monthly averaged profile is removed as the background from each measurement raw profile. Then, the residual profile is filtered by a high-pass filter to extract gravity wave perturbations. Given that the vertical wavelengths of low atmospheric gravity waves are typically shorter than $10 \mathrm{~km}$, the cut-off vertical wavelength of the high-pass filter is chosen to be $10 \mathrm{~km}$. Then, a low-pass filter with a wavelength of $1 \mathrm{~km}$ is applied to the residual components to exclude the influence of eddies. Finally, the filtered profile can be seen as gravity wave perturbations. The total gravity energy density $E$, that is, kinetic energy density plus potential energy density, can be calculated from the zonal wind perturbation $\left(u^{\prime}\right)$, meridional wind perturbation $\left(v^{\prime}\right)$, and temperature perturbation $\left(T^{\prime}\right)$ :

$$
E=\frac{1}{2}\left(\overline{u^{\prime 2}}+\overline{v^{\prime 2}}+\frac{1}{2} \frac{g^{2} \overline{T^{\prime 2}}}{N^{2} \overline{T^{2}}}\right)
$$

where $\bar{T}$ is monthly averaged background temperature, $g$ is gravity acceleration; and overbars over the square of gravity wave perturbations denote an average over a wavelength span, which is realized by a low-pass filter with a cut-off vertical wavelength of $10 \mathrm{~km}$. $E$ differs among days. Then, the absolute time difference per second of $E$ is estimated by

$$
E_{T}^{\prime}(i)=\left|\frac{\partial E}{\partial T}\right|=|E(t)-E(t-1)| /(24 * 3600)
$$


where $E(t-1)$ is the energy profile from one day prior. The wave energy per unit volume can be described as $E_{V}=\bar{\rho} E$, where $\bar{\rho}$ is monthly averaged background mass density. In the absence of energy dissipation and energy transport, $E_{V}$ should keep a constant altitude value under the assumption that the main energy of waves transports from bottom to top. Therefore, $E_{V}$ 's increase with height implies the injection of energy into waves, and its decrease with height denotes gradual energy dissipation. Hence, the height difference of $E_{V}$ can represent the variation of gravity wave energy. We define the variation of gravity waves at the $i$ th height as

$$
E_{V Z}^{\prime}=-\frac{\partial E_{T}}{\partial z}=\left(E_{V}^{i-1}-E_{V}^{i+1}\right) / 2 z
$$

where $E_{V}^{i-1}$ and $E_{V}^{i+1}$ are total energy densities at the $(i-1)$ th and $(i+1)$ th heights, respectively. Accordingly, $E_{V Z}^{\prime}>0$ and $E_{V Z}^{\prime}<0$ demonstrate energy dissipation and injection, respectively.

Figure 7 demonstrates the variations of $E, E_{V}, E_{T}^{\prime}$, and $E_{V Z}^{\prime} . E$ and $E_{V}$ are much more intense in winter and spring below $17 \mathrm{~km}$ in most cases and are much smaller in the lower stratosphere, as presented in Fig. 7(a) and 7(c). The most significant regions of $E$ and $E_{V}$ are in the height range of $7-17 \mathrm{~km}$ and below $5 \mathrm{~km}$; these regions have maxima reaching approximately $40 \mathrm{~J} / \mathrm{kg}$ and $30 \mathrm{~J} / \mathrm{m}^{3} . E_{T}^{\prime}$ is roughly estimated and exhibits similar variations with $E$, with comparable magnitude with $\varepsilon$. Figure 7(d) displays that the rapid energy loss and injection regions for waves alternately appear below $15 \mathrm{~km}$ with maximal (minimal) up (down) to $0.01(-0.01) \mathrm{J} / \mathrm{m}^{3} / \mathrm{m}$. In addition, waves lose energy in the $15-25 \mathrm{~km}$ height range.

The correlation coefficients between $E_{V}$ and $R i_{C}\left(R_{E_{V}-R i_{C}}\right.$ hereafter) and between $E_{V}$ and $R i_{1}\left(R_{E_{V}-R i_{1}}\right.$ hereafter $)$ and the ratio of $E_{T}^{\prime}$ to $\varepsilon\left(E_{T}^{\prime} / \varepsilon\right)$ and $\left|E_{V Z}^{\prime}\right|$ to $\varepsilon$ 
$\left(\left|E_{V Z}^{\prime}\right| / \mathcal{E}\right)$ are displayed in Fig. 8. Figure 8(a) and 8(b) highlight that $R_{E_{V}-R_{C}}$ and $R_{E_{V}-R i_{1}}$ show weak or strong positive correlations at all the investigated heights and have maxima reaching 0.8 . The high positive $R_{E_{V}-R_{C}}$ values imply that shear instability is an important source to waves or propagating waves can improve the occurrence rate of instabilities, whereas the high positive $R_{E_{V}-R_{1}}$ values may suggest that the propagating waves can contribute to the reduction of $R i$, especially in the middle troposphere and the tropopause regions. Figure 8(c) displays that the ratios of $E_{T}^{\prime} / \varepsilon$ range from 0.2 to 0.9 with a maximum at approximately $13 \mathrm{~km}$. Note that this ratio is less than one at different heights. This condition indicates that the temporal variation of gravity waves may be able to predict turbulent dissipation rates at different heights. Another important role of waves in turbulence is that breaking gravity waves may directly generate turbulence. Figure $8(\mathrm{~d})$ demonstrates that $\left|E_{V Z}^{\prime}\right| / \mathcal{E}$ decreases from approximately $9 \mathrm{kgsm}^{-4}$ at $5 \mathrm{~km}$ to nearly $0 \mathrm{kgsm}^{-4}$ in the lower stratosphere. The spatial variations of wave energy in the troposphere may have sufficient energy for turbulence. $\left|E_{V Z}^{\prime}\right| / \mathcal{E}$ decreases quickly with altitude above $15 \mathrm{~km}$, accompanied with strong wind shear. This situation may suggest that breaking wave energy is quickly transferred to turbulence in the CPT region.

\section{Conclusions}

Statistically, long-term variations of turbulence in the lower atmosphere and their associations with inertial gravity waves are revealed in this study. The advantage of using the radiosonde site at Miramar Nas $\left(32.8^{\circ} \mathrm{N}, 117.1^{\circ} \mathrm{W}\right)$ is that its results can be compared with those from the MST radar at California $\left(34.46^{\circ} \mathrm{N}, 120.33^{\circ} \mathrm{W}\right)$. Furthermore, this kind of 
comparison is rare in recent studies.

The spatial variations of turbulence show enormous variations and significant seasonal cycles. The magnitude of the energy dissipation rate is consistent with that found by Nastrom and Easton (2005), but large differences appear in the height range of $5 \mathrm{~km}$ to $12 \mathrm{~km}$. The Thorpe-resolved dissipation rate is based on the thermal characteristics of the atmosphere, whereas radar-resolved turbulence is characterized by wind fields. This difference may deeply affect the detection of turbulence. However, encouraging argument is found between diffusion rates. The energy dissipation rate is lognormally distributed and is generally larger for a smaller $R i$. Over half of the turbulence can exist beyond the region where $R i$ equals 1, making $R i$ not a good predictor of the existence of turbulence. Propagating gravity waves in the lower free atmosphere can reduce the value of $R i$. Therefore, it can promote the activity of turbulence indirectly, especially in the middle troposphere and the tropopause regions. Another important role of gravity waves is that the breaking energy may produce wave-induced turbulence accompanied by strong wind shear, especially in the CPT region. The temporal variation of energy is an interesting parameter and keeps a ratio less than 1 with dissipation rate at different heights. This condition implies that the temporal variation of wave may have the potential to roughly estimate turbulent dissipation rates at different heights.

Acknowledgements. This work was jointly supported by the National Natural Science Foundation of China (through grants 41531070 and 41521063). The adopted data were freely downloaded from the Stratospheric Processes and Their Role in Climate Data Center 
Ann. Geophys. Discuss., https://doi.org/10.5194/angeo-2018-114

Manuscript under review for journal Ann. Geophys.

Discussion started: 14 November 2018

(c) Author(s) 2018. CC BY 4.0 License.

\section{References}

Barat, J.: Some characteristics of clear air turbulence in the middle stratosphere, J. Atmos. Sci., 39, 2553-2564, 1982.

Cho, J. Y. N., Newell, R. E., Anderson, B. E., Barrick, J. D. W., and Thornhill, K. L.: Characterizations of tropospheric turbulence and stability layers from aircraft observations, J. Geophys. Res., 108(D20), 8784, doi:10.1029/2002JD002820, 2003.

Clayson, C. A., and Kantha, L.: On turbulence and mixing in the free atmosphere inferred from high-resolution soundings, J. Atmos. Oceanic Technol., 25, 833-852, doi:10.1175/2007JTECHA992.1, 2008.

Crawford, W. R.: A comparison of length scales and decay times of turbulence in stratified flows, J. $\quad$ Phys. $\quad$ Oceanogr., $\quad 16, \quad 1847-1854$, doi:10.1175/1520-0485(1986)016<1847:ACOLSA>2.0.CO;2, 1986.

Das, S. S., Ghosh, A. K., Satheesan, K., Jain, A. R., and Uma, K. N.: Characteristics of atmospheric turbulence in terms of background atmospheric parameters inferred using MST radar at Gadanki $\left(13.5^{\circ} \mathrm{N}, \quad 79.2^{\circ} \mathrm{E}\right), \quad$ Radio $\quad$ Sci., $\quad 45, \quad \mathrm{RS} 4008$, doi:10.1029/2009RS004256, 2010.

Durran, D. R., and Klemp, J.: On the effects of Moisture on the Brunt-Väisälä Frequency, J. Atmos. Sci., 39, 2152-2158, 1982.

Dutta, G., Ajay Kumar, M. C., Vinay Kumar, P., Rao, P. V., Bapiraju, B., and Aleem Bash, H.: High resolution observations of turbulence in the troposphere and lower 


$$
\text { stratosphere over Gadanki, Ann. Geophys., 27, 2407-2415, }
$$
doi:10.5194/angeo-27-2407-2009, 2009.

Fritts, D. C., Garten, J. F., and Andreassen, O.: Wave breaking and transition to turbulence in stratified shear flows, J. Atmos. Sci., 53, 1057-1085, 1996.

Fritts, D. C., and Alexander, M. J.: Gravity wave dynamics and effects in the middle atmosphere, Rev. Geophys., 41(1), 1003, doi:10.1029/ 2001RG000106, 2003.

Fritts, D. C., Bizon, C., Werne, J. A., and Meyer, C. K.: Layering accompanying turbulence generation due to shear instability and gravity wave breaking, J. Geophys. Res., 108(D8), 8452, doi:10.1029/2002JD002406, 2003.

Fritts, D. C., Wan, K., Franke, P. M., and Lund, T.: Computation of clear-air radar backscatter from numerical simulations of turbulence: 3. Off-zenith measurements and biases throughout the lifecycle of a Kelvin-Helmholtz instability, J. Geophys. Res., 117, D17101, doi:10.1029/2011JD017179, 2012.

Fritts, D. C., Smith, R. B., Taylor, M. J., Doyle, J. D., Eckermann, S. D., Dörnbrack, A., et al.: The Deep Gravity Wave Experiment (DEEPWAVE): An airborne and ground-based exploration of gravity wave propagation and effects from their sources throughout the lower and middle atmosphere, Bull. Am. Meteorol. Soc., 97(3), 425-453, doi:10.1175/BAMS-D-14-00269.1, 2016.

Fritts, D. C., Wang, L., Geller, M. A., Lawrence, D. A., Werne, J., and Balsley, B. B.: Numerical Modeling of Multiscale Dynamics at a High Reynolds Number: Instabilities, Turbulence, and an Assessment of Ozmidov and Thorpe Scales, J. Atmos. Sci, 73(2), $555-578,2016$. 
Ann. Geophys. Discuss., https://doi.org/10.5194/angeo-2018-114

Manuscript under review for journal Ann. Geophys.

Discussion started: 14 November 2018

(c) Author(s) 2018. CC BY 4.0 License.

Fujiwara, M., Yamamoto, M. K., Hashiguchi, H., Horinouchi, T., and Fukao, S.: Turbulence at the tropopause due to breaking Kelvin waves observed by the equatorial atmosphere radar, Geophys. Res. Lett., 30(4), 1171, doi:10.1029/2002GL016278, 2003.

Furumoto, J., and Tsuda, T.: Characteristics of energy dissipation rate and effect of humidity on turbulence echo power revealed by MU radar-RASS Measurements, J. Atmos. Sol. Terr. Phys., 63, 285-294, 2001.

Gavrilov, N. M., Luce, H., Crochet, M., Dalaudier, F., and Fukao, S.: Turbulence Parameter Estimations from High-Resolution Balloon Temperature Measurements of the MUTSI-2000 campaign, Ann. Geophys., 23, 2401-2413, 2005.

Haack, A., Gerding, M., and Lübken, F.-J.: Characteristics of stratospheric turbulent layers measured by LITOS and their relation to the Richardson number, J. Geophys. Res., 119, 10605-10618, doi:10.1002/2013JD021008, 2014.

Hocking, W. K. and Mu, K. L.: Upper and middle tropospheric kinetic energy dissipation rates from measurements of $\bar{C}_{n}^{2}$-review of theories, in-situ investigations, and experimental studies using the Buckland Park atmospheric radar in Australia, J. Atmos. Sol. Terr. Phys., 59, 1779-1803, 1997.

Kantha, L., and Hocking, W.: Dissipation rate of turbulence kinetic energy in the free atmosphere: MST radar and radiosondes, J. Atmos. Sol. Terr. Phys., 73(9), 1043-1051, doi:10.1016/j.jastp.2010.11.024, 2011.

Kunkel, D., Hoor, P., and Wirth, V.: Can inertia-gravity waves persistently alter the tropopause inversion layer?, Geophys. Res. Lett, 41(22), 7822-7829, doi:10.1002/2014GL061970, 2014. 
Ann. Geophys. Discuss., https://doi.org/10.5194/angeo-2018-114

Manuscript under review for journal Ann. Geophys.

Discussion started: 14 November 2018

(c) Author(s) 2018. CC BY 4.0 License.

Liu, A. Z.: Estimate eddy diffusion coefficients from gravity wave vertical momentum and heat fluxes, Geophys. Res. Lett., 36, L08806, doi:10.1029/2009GL037495, 2009.

Liu, H.-L., Hays, P. B., and Roble, R. G.: A numerical study of gravity wave breaking and impacts on turbulence and mean state, J. Atmos. Sci., 56, 2152-2177, 1999.

Li, Q., Rapp, M., Schrön, A., Schneider, A., and Stober G.: Derivation of turbulent energy dissipation rate with MAARSY and radiosondes at Andoya, Norway, Ann. Geophys., 34, 1209-1229, doi:10.5194/angeo-34-1209-2016, 2016.

Lovejoy, S., Tuck, A. F., Hovde, S. J., and Schertzer, D.: Is isotropic turbulence relevant in the atmosphere?, Geophys. Res. Lett., 34, L15802, doi:10.1029/2007GL029359, 2007.

Lübken, F.-J.: Seasonal variation of turbulent energy dissipation rates at high latitudes as determined by in situ measurements of neutral density fluctuations, J. Geophys. Res., 102, 13441-13456, 1997.

Luce, H., Fukao, S., Yamamoto, M., Sidi, C., and Dalaudier, F.: Validation of winds measured by MU radar with GPS radiosondes during the MUTSI campaign, J. Atmos. Oceanic Technol., 18, 817-829, 2001.

Mater, B. D., Schaad, S. M., and Venayagamoorthy, S. K.: Relevance of the Thorpe length scale in stably stratified turbulence, Phys. Fluids, 25, 076604, doi:10.1063/1.4813809, 2013.

Mater, B. D., Venayagamoorthy, S. K., Laurent, L. S., and Moum, J. N.: Biases in Thorpe scale estimates of turbulence dissipation. Part I: Assessments from large-scale overturns in oceanographic data, J. Phys. Oceanogr., 45, 2497-2521, doi:https://doi.org/10.1175/JPO-D-14-0128.1, 2015. 
Mega, T., Yamamoto, M. K., Luce, H., Tabata, Y., Hashiguchi, H., Yamamoto, M., Yamanaka, M. D., and Fukao, S.: Turbulence generation by Kelvin-Helmholtz instability in the tropical tropopause layer observed with a $47 \mathrm{MHz}$ range imaging radar, J. Geophys. Res., 115, D18115, doi:10.1029/2010JD013864, 2010.

Nastrom, G. D, and Eaton, F. D.: Turbulence eddy dissipation rates from radar observations at 5-20 km at White Sands Missile Range: New Mexico, J. Geophys. Res., 102(D16), 19495-19505, 1997.

Nastrom, G. D., and Eaton, F. D.: Seasonal variability of turbulence parameters at 2 to $21 \mathrm{~km}$ from MST radar measurements at Vandenberg Air Force Base, California, J. Geophys. Res., 110, D19110, doi:10.1029/2005JD005782, 2005.

NOAA: U. S. Standard Atmosphere, NOAA-S/T 76-1562, 19pp, 1976.

Ozmidov, R. V.: On the turbulence exchange in a stably stratified ocean, Atmos. Atmos. Oceanic Phys., 8, 853-860, 1965.

Pavelin, E., Whiteway, J. A., Busen, R., and Hacker, J.: Airborne observations of turbulence, mixing, and gravity waves in the tropopause region, J. Geophys. Res., 107, D104084, doi:10.1029/2001JD000775, 2002.

Pramitha, M., Venkat Ratnam, M., Taori, A., Krishna Murthy, B. V., Pallamraju, D., and Vijaya Bhaskar Rao, S.: Evidence for tropospheric wind shear excitation of high-phase-speed gravity waves reaching the mesosphere using the ray-tracing technique, Atmos. Chem. Phys., 15, 2709-2721, doi:10.5194/acp-15-2709-2015, 2015.

Rao, D. N., Rao, T. N., Venkataratnam, M., Thulasiraman, S., and Rao, S. V. B.: Diurnal and seasonal variability of turbulence parameters observed with Indian MST Radar, Radio 
Sci., 36, 1439-1457, 2001.

Riley, J. J., and Lindborg, E.: Straitified turbulence: A possible interpretation of some geophysical turbulence measurements, J. Atmos. Sci., 65, 2416-2424, 2008.

Satheesan, K., and Krishna Murthy, B. V.: Turbulence parameters in the tropical troposphere and lower stratosphere, J. Geophys. Res., 107, D14002, doi:10.1029/2000JD000146, 2002.

Schneider, A., Gerding, M., and Lübken F.-J.: Comparing turbulent parameters obtained from LITOS and radiosonde measurements. Atmos. Chem. Phys, 15: 2159-2166, doi: https://doi.org/10.5194/acp-15-2159-2015, 2015.

Scotti, A.: Biases in Thorpe-scale estimates of turbulence dissipation. Part II: energetics arguments and turbulence simulations, J. Phys. Oceanogr., 45(10), 2522-2543, doi: https://doi.org/10.1175/JPO-D-14-0092.1, 2015.

Sharman, R. D., Trier, S. B., Lane, T. P., and Doyle, J. D.: Sources and dynamics of turbulence in the upper troposphere and lower stratosphere: A review, Geophys. Res. Lett., 39, L12803, doi:10.1029/2012GL051996, 2012.

Sharman, R. D., Cornman, L. B., Meymaris, G., Pearson, J., and Farrar, T.: Description and derived climatologies of automated in situ eddy-dissipation-rate reports of atmospheric turbulence, J. Appl. Meteorol. Climatol., 53(6), 1416-1432, 2014.

Theuerkauf, A., Gerding, M., and Lübken, F.-J.: LITOS-A new balloon-borne instrument for fine-scale turbulence soundings in the stratosphere, J. Atmos. Meas. Tech., 4, 55-66, 2011.

Thorpe, S. A.: Experiments on instability and turbulence in a stratified shear flow, Boundary 
Ann. Geophys. Discuss., https://doi.org/10.5194/angeo-2018-114

Manuscript under review for journal Ann. Geophys.

Discussion started: 14 November 2018

(c) Author(s) 2018. CC BY 4.0 License.

Layer Meteorol., 5, 95-119, doi:10.1007/BF02188314, 1973.

Thorpe, S. A.: The Turbulent Ocean, Cambridge Univ. Press, Cambridge, U. K, 2005.

Ueda, H., Fukui, T., Kajino, M., Horiguchi, M., Hashiguchi, H., Fukao, S.: Eddy diffusivities for momentum and heat in the upper troposphere and lower stratosphere measured by MU radar and RASS, and a comparison of turbulence model predictions, J. Atmos. Sci., 69, $323-337,2012$.

Whiteway, J. A., Klaassen, G. P., Bradshaw, N. G., and Hacker, J.: Transition to Turbulence in Shear above the Tropopause, Geophys. Res. Lett., 31, L02118, doi:10.1029/2003GL018509, 2004.

Wijesekera, H. W., Dillon, T. M., and Padman, L.: Some statistical and dynamical properties of turbulence in the oceanic pycnocline, J. Geophys. Res., 98, 22665-22679, doi:10.1029/93JC02352,1993.

Wilson, R., Dalaudier, F., and Bertin, F.: Estimate of the turbulent fraction in the free atmosphere from MST radar measurements, J. Atmos. Oceanic Technol., 22, 1326-1339, 2005.

Wilson, R., Luce, H., Dalaudier, F., and Lafrere, J.: Turbulence patch identification in potential density or temperature profiles, J. Atmos. Oceanic Technol., 27. doi:10.1175/2010JTECHA1357.1, 2010.

Wilson, R., Dalaudier, F., and Luce, H.: Can one detect small-scale turbulence from standard meteorological radiosondes?, Atmos. Meas. Tech. 4, 795-804, doi:10.5194/amt-4-795-2011, 2011.

Yagi, M., and Yasuda, I.: A modified method for estimating vertical profiles of turbulent 
Ann. Geophys. Discuss., https://doi.org/10.5194/angeo-2018-114

Manuscript under review for journal Ann. Geophys.

Discussion started: 14 November 2018

(c) Author(s) 2018. CC BY 4.0 License.

dissipation rate using density inversions in the Kuril straits, J. Oceanogr., 69(2), 203-214, 2013.

Yamada, Y., Fukunishi, H., Nakamura, T., and Tsuda, T.: Breakdown of small-scale quasi-stationary gravity wave and transition to turbulence observed in $\mathrm{OH}$ airglow, Geophys. Res. Lett., 28, 2153-2156, 2001.

Zhang, J., Chen, H., Li, Z., Fan, X., Peng, L., Yu, Y., and Cribb, M.: Analysis of cloud layer structure in Shouxian, China using RS92 radiosonde aided by $95 \mathrm{GHz}$ cloud radar, J. Geophys. Res., 115, D00K30, doi:10.1029/2010JD014030.FF, 2010.

Zhang, S. D., Yi, F., Huang, C. M., and Huang, K. M.: High vertical resolution analyses of gravity waves and turbulence at a mid-latitude station, J. Geophys. Res., 117, D02103, doi:10.1029/2011JD016587, 2012.

Zhang, S. D., Yi, F., Huang, C. M., Huang, K. M., Gan, Q., Zhang, Y. H., and Gong, Y.: Latitudinal and altitudinal variability of lower atmospheric inertial gravity waves revealed by U.S. radiosonde data, J. Geophys. Res., 118, 7750-7764, doi:10.1002/jgrd.50623, 2013.

Zhang, Y. H., Zhang, S. D., and Yi, F.: Intensive radiosonde observations of lower tropospheric inversion layers over Yichang, China, J. Atmos. Sol. Terr. Phys., 71, 180190, doi:10.1016/j.jastp.2008.10.008, 2009. 
Ann. Geophys. Discuss., https://doi.org/10.5194/angeo-2018-114

Manuscript under review for journal Ann. Geophys.

Discussion started: 14 November 2018

(c) Author(s) 2018. CC BY 4.0 License.

\section{Figures}

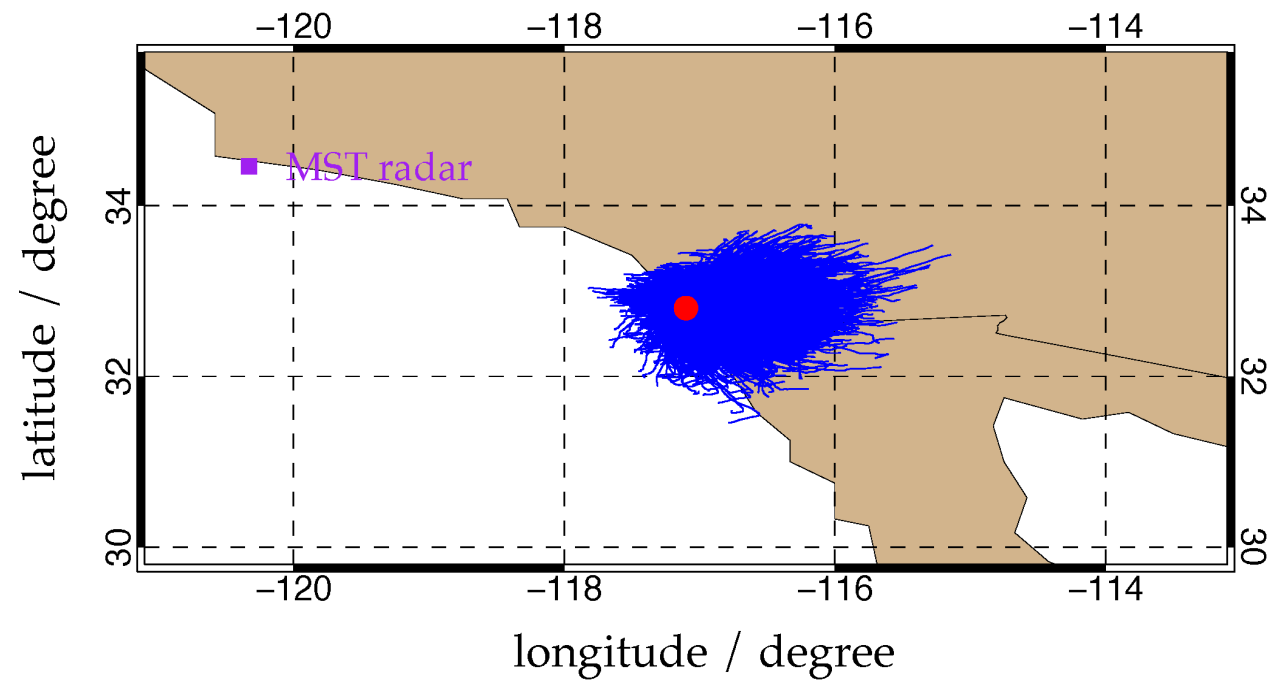

Figure 1. Distribution map of the cumulative horizontal trajectories of all radiosondes released at Miramar Nas. The red dot highlights the location of the radiosonde site, and the purple square denotes the position of the MST radar at Vandenberg Air Force Base, California. 
Ann. Geophys. Discuss., https://doi.org/10.5194/angeo-2018-114

Manuscript under review for journal Ann. Geophys.

Discussion started: 14 November 2018

(c) Author(s) 2018. CC BY 4.0 License.
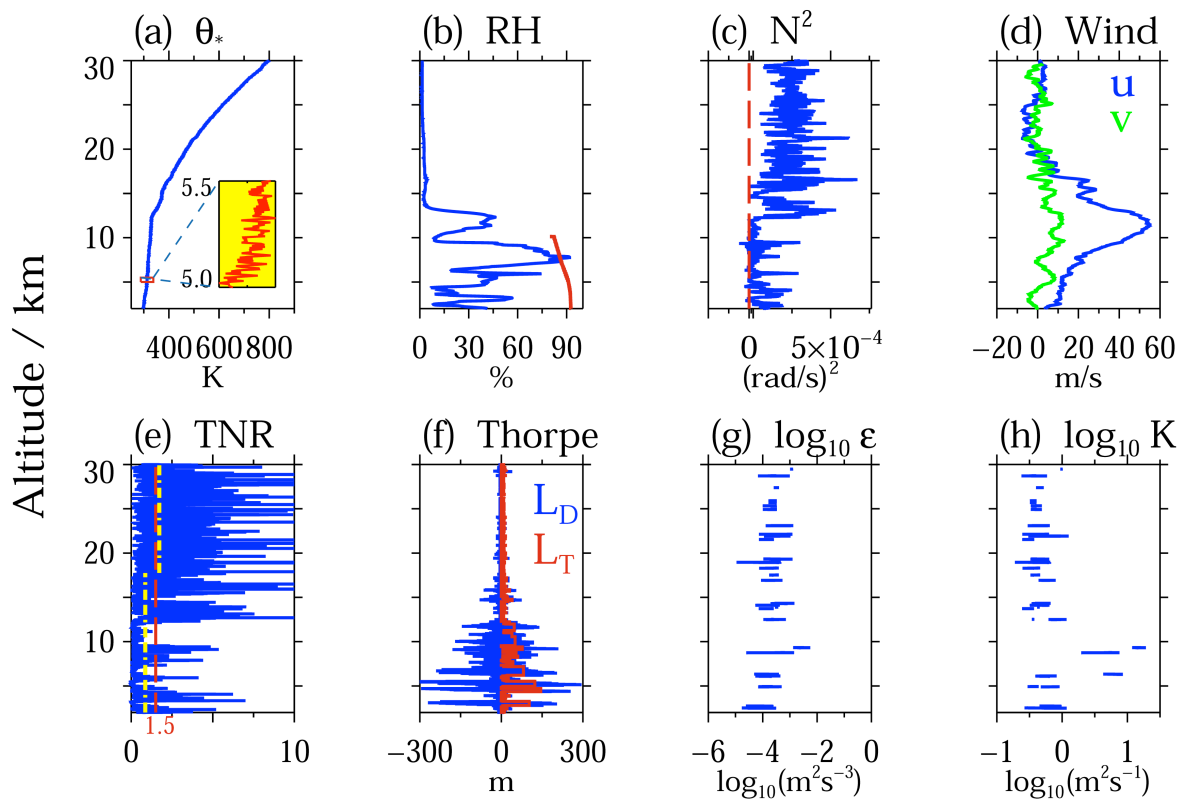

Figure 2. Typical vertical profiles of atmospheric and turbulent parameters: (a) composite potential temperature, (b) relative humility (The red line presents the empirical thresholds for clouds.), (c) squared Brunt-Väisälä frequency, (d) zonal $(u)$ and meridional $(v)$ wind velocities, (e) local-TNR (The long red dashed line shows the threshold for $\varsigma=1.5$, and the two yellow dotted lines present bulk TNR $\bar{\zeta}$ in the troposphere and the stratosphere, respectively.), (f) Thorpe displacement $L_{D}$ and Thorpe length $L_{T}$, (g) the logarithm of the turbulent energy dissipation rate, and (h) the logarithm of the eddy diffusion coefficient at 0012 UT on March 12, 2018. 
Ann. Geophys. Discuss., https://doi.org/10.5194/angeo-2018-114

Manuscript under review for journal Ann. Geophys.

Discussion started: 14 November 2018

(c) Author(s) 2018. CC BY 4.0 License.

(a) Zonal wind

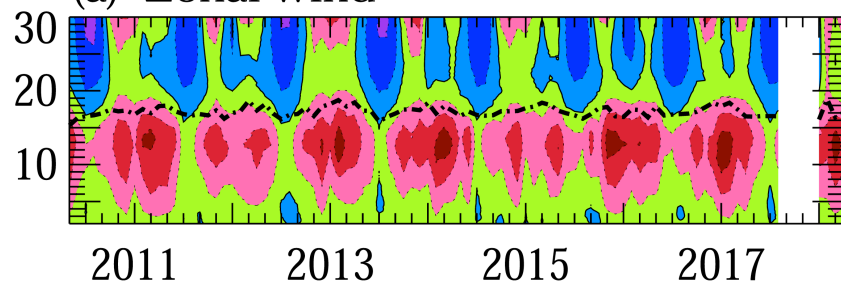

$\mathrm{m} / \mathrm{s}$

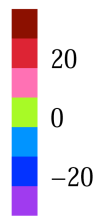

$-20$

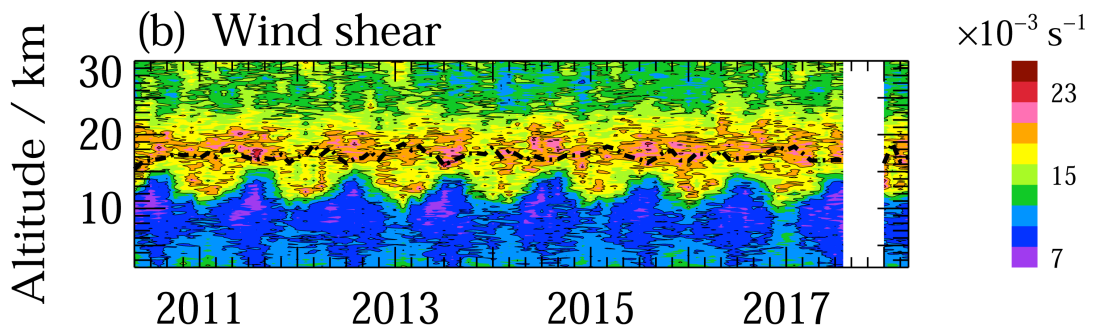

(c) $\mathrm{N}^{-2}$

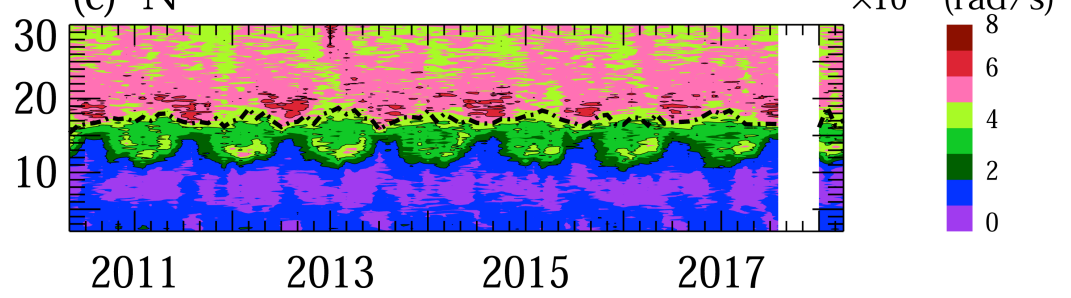

Figure 3. Monthly average of (a) zonal wind, (b) vertical shear of horizontal wind speed, and (c) the square of Brunt-Väisälä frequency. The blank denotes no measurement, and the dotted lines illustrate the height of CPT. 
Ann. Geophys. Discuss., https://doi.org/10.5194/angeo-2018-114

Annales

Manuscript under review for journal Ann. Geophys.

Discussion started: 14 November 2018

(c) Author(s) 2018. CC BY 4.0 License.

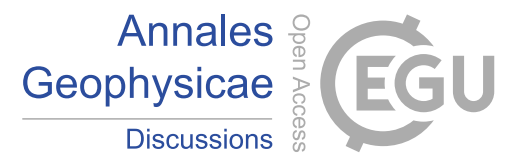

(c) (1)

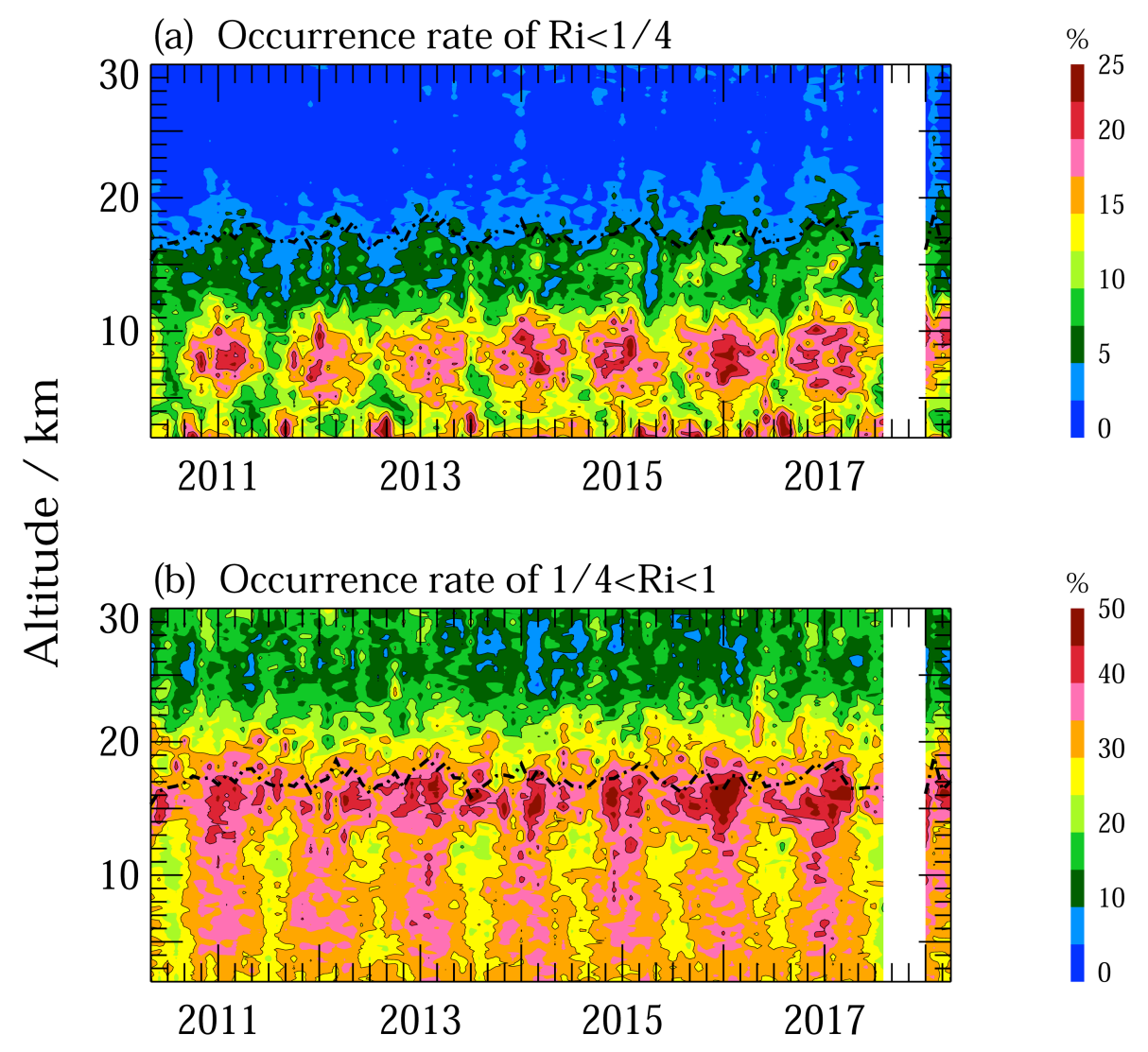

Figure 4. Monthly occurrence rates for $R i<1 / 4$ and $1 / 4 \leq R i<1$. The blank denotes no measurement, and the dotted lines illustrate the height of CPT. 
Ann. Geophys. Discuss., https://doi.org/10.5194/angeo-2018-114

Manuscript under review for journal Ann. Geophys.

Discussion started: 14 November 2018

(c) Author(s) 2018. CC BY 4.0 License.

(a) Thorpe length

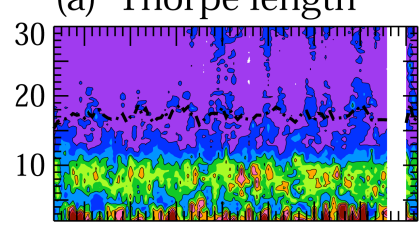

$20112013 \quad 2015 \quad 2017$
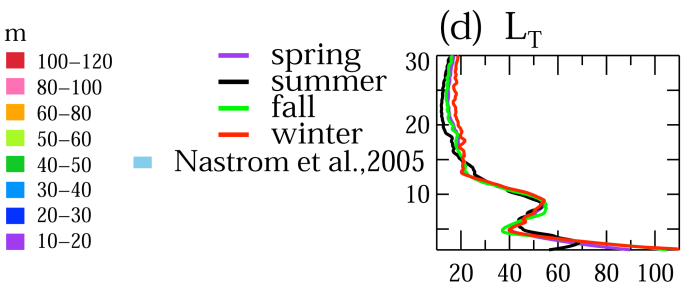

$\log _{10}\left(\mathrm{~m}^{2} \mathrm{~s}^{-3}\right)$

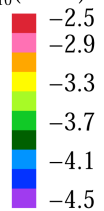

$2011 \quad 2013 \quad 2015 \quad 2017$

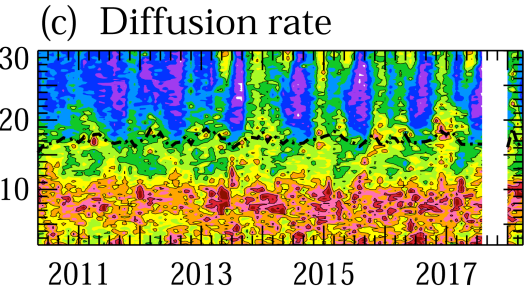

(e) $\log _{10} \varepsilon$

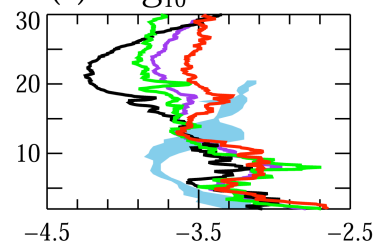

(f) $\log _{10} \mathrm{~K}$

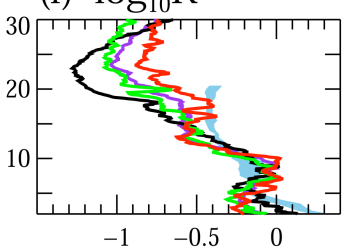

Figure 5. Monthly averaged (a) Thorpe length, (b) energy dissipation rate, and (c) diffusion rate. (d)-(f) present the seasonal results. The blank denotes no measurement, the dotted lines illustrate the height of CPT, and the light blue areas in (e) and (f) show the results from Nastrom and Easton (2005). 
Ann. Geophys. Discuss., https://doi.org/10.5194/angeo-2018-114

Annales

Manuscript under review for journal Ann. Geophys.

Discussion started: 14 November 2018

(c) Author(s) 2018. CC BY 4.0 License.

Discussions

(c) (1)

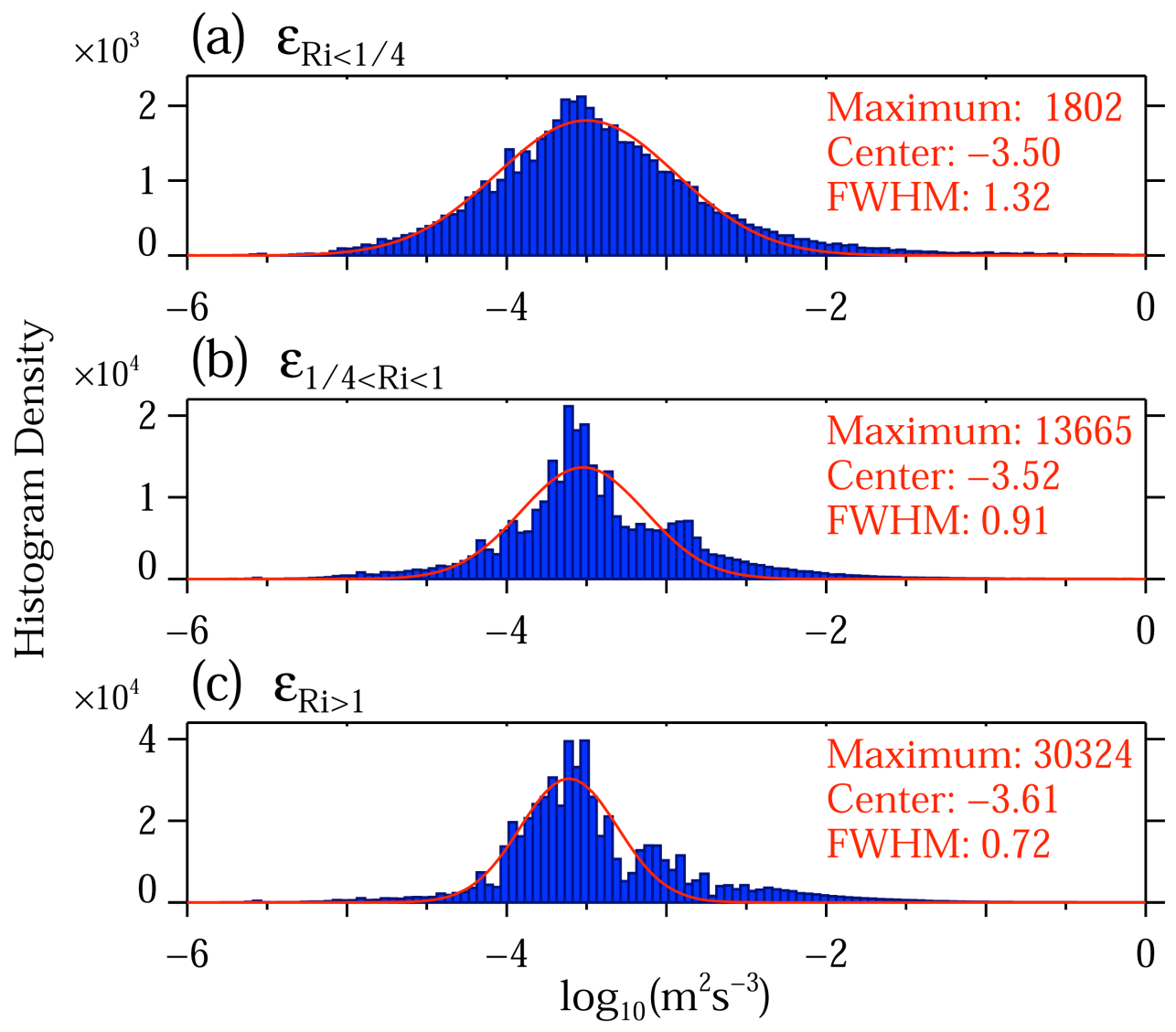

Figure 6. The histogram densities of energy dissipation rates that match $R i<1 / 4$, $1 / 4 \leq R i<1$, and $R i \geq 1$. The red solid curves are the Gaussian fit to the densities, and the maximum, center and full width at half maximum (FWHM) values are noted. 
Ann. Geophys. Discuss., https://doi.org/10.5194/angeo-2018-114 Manuscript under review for journal Ann. Geophys.

Discussion started: 14 November 2018

(c) Author(s) 2018. CC BY 4.0 License.
Annales Geophysicae

Discussions

(c) (i)
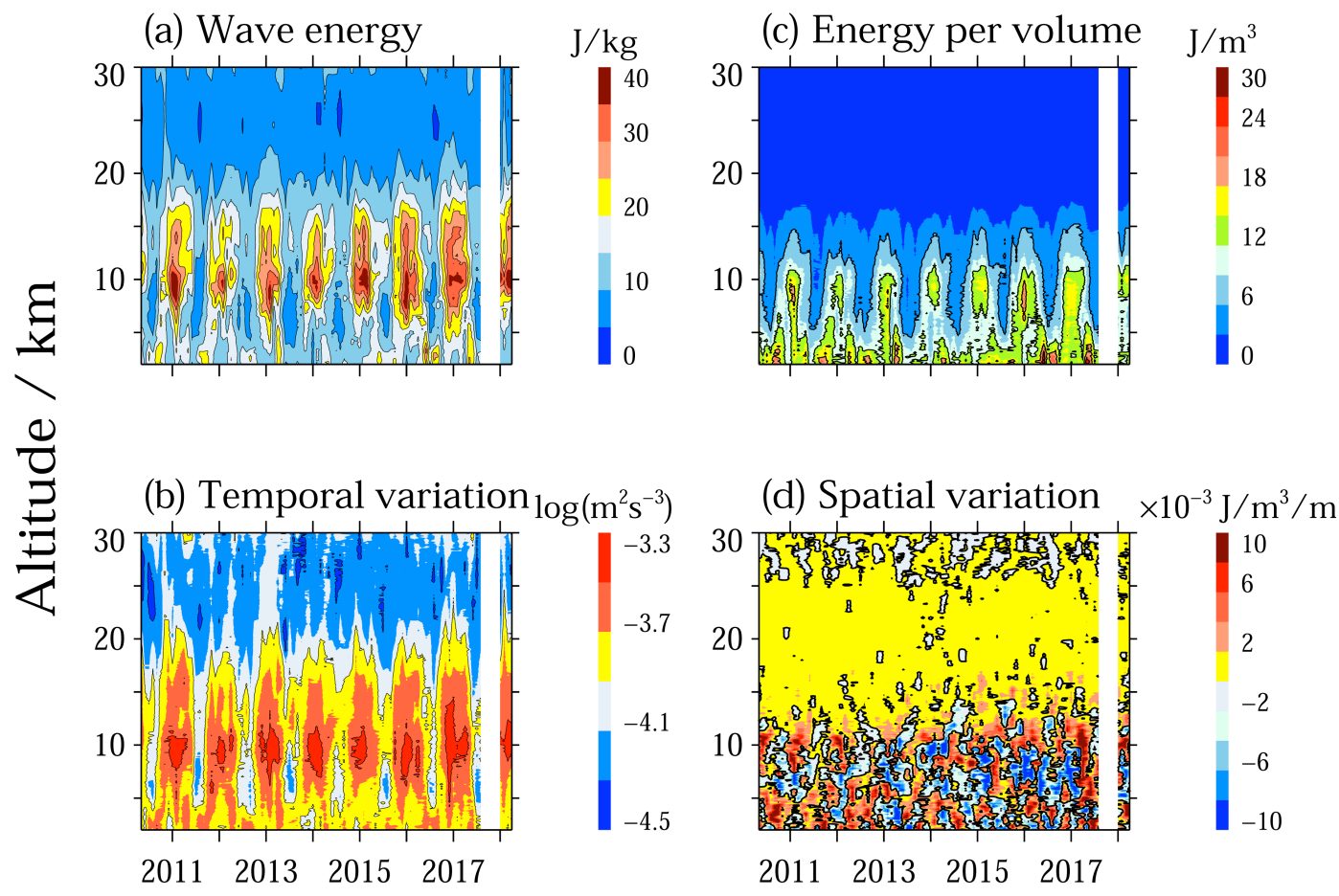

Figure 7. (a) Monthly averaged gravity wave energy density $E$, (b) temporal variations of wave energy, (c) monthly averaged gravity wave energy per volume $E_{V}$, and (d) spatial variations of wave energy. The vertical blank denotes no measurement. 
Ann. Geophys. Discuss., https://doi.org/10.5194/angeo-2018-114

Manuscript under review for journal Ann. Geophys.

Discussion started: 14 November 2018

(c) Author(s) 2018. CC BY 4.0 License.
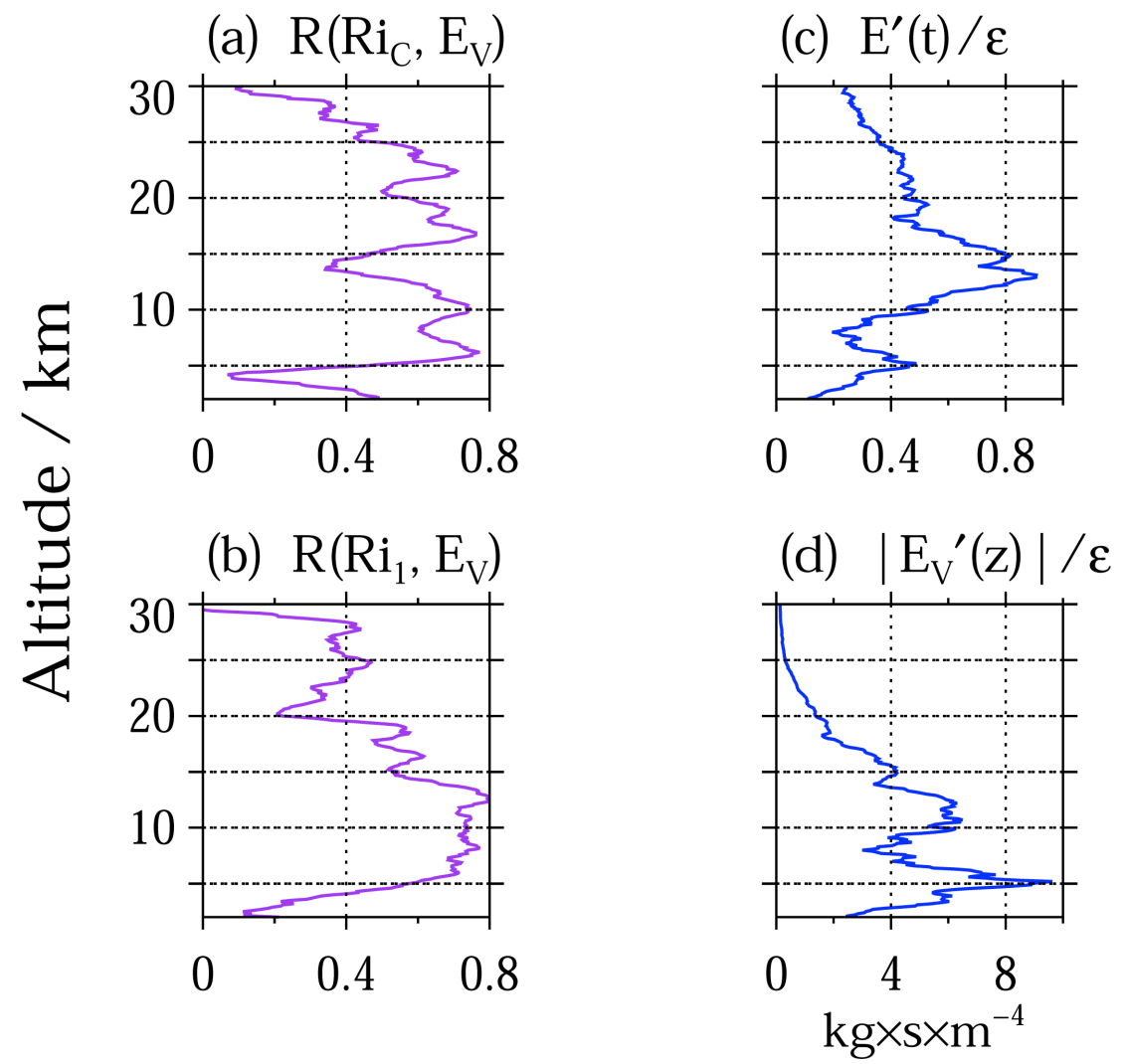

Figure 8. Correlation coefficients (a) between wave energy per volume and occurrence rate of $R i<1 / 4$ and (b) between wave energy per volume and $1 / 4 \leq R i<1$. Averaged ratios in all seasons of (c) $E_{T}^{\prime}$ to energy dissipation rate and (d) $\left|E_{V Z}^{\prime}\right|$ to energy dissipation rate. 